\title{
O ANALFABETISMO NO BRASIL: LIÇÕES DA HISTÓRIA
}

\author{
EL ANALFABETISMO EN BRASIL: LECCIONES DE LA HISTORIA
}

THE ILLITERACY IN BRAZIL: LESSONS FROM HISTORY

\author{
Ana Carolina BRAGA ${ }^{1}$ \\ Francisco José Carvalho MAZZEU ${ }^{2}$
}

RESUMO: O artigo aborda o problema do analfabetismo no Brasil, procurando revelar suas raízes históricas e sociais. Parte-se de uma análise dos dados que afasta a leitura otimista baseada na queda gradativa dos índices. Nem a queda pode ser considerada significativa, quando se observam o número absoluto de analfabetos e as tendências da série histórica dos dados, nem se pode atribuir essa redução aos resultados de políticas públicas efetivas. Fazendo um estudo histórico, percebe-se que as relações econômicas, políticas e sociais acabam por determinar as condições em que vai ocorrer a oferta de escolarização, quem terá acesso a ela, qual será sua possibilidade de progresso, entre outros aspectos. Ao mesmo tempo, as estruturas do ensino têm estado à mercê dessa dinâmica econômico-social, deixando de buscar uma organização que ofereça oportunidades reais de desenvolvimento a todos os alunos.

PALAVRAS-CHAVE: Analfabetismo. Alfabetização. Políticas públicas de alfabetização.

RESUMEN: El artículo aborda el problema del analfabetismo en Brasil, buscando revelar sus raíces históricas y sociales. Se parte de un análisis de los datos que aleja la lectura optimista basada en la caída gradual de los índices. Ni la caída puede ser considerada significativa, cuando se observan el número absoluto de analfabetos y las tendencias de la serie histórica de los datos, ni se puede atribuir esa reducción a los resultados de políticas públicas efectivas. Al realizar un estudio histórico, se percibe que las relaciones económicas, políticas y sociales acaban por determinar las condiciones en que va a ocurrir la oferta de escolarización, quién tendrá acceso a ella, cuál será su posibilidad de progreso, entre otros aspectos. Al mismo tiempo, las estructuras de la enseñanza han estado a merced de esa dinámica económico-social, dejando de buscar una organización que ofrezca oportunidades reales de desarrollo a todos los alumnos.

PALABRAS CLAVE: Analfabetismo. Alfabetización. Políticas públicas de alfabetización.

${ }^{1}$ Mestre em Educação pelo Programa de Pós-Graduação em Educação Escolar da Faculdade de Ciências e Letras da UNESP/Campus de Araraquara. E-mail: anacbraga@live.com.

${ }^{2}$ Doutor em Educação pela UFSCar e Docente do Programa de Pós-Graduação em Educação Escolar da Faculdade de Ciências e Letras da UNESP/Campus de Araraquara. E-mail: mazzeu@fclar.unesp.br. 
ABSTRACT: The article discusses the problem of illiteracy in Brazil, seeking to reveal their historical and social roots. It starts from an analysis of the data that leaves an optimistic reading on the gradual fall of the indices. Neither can the fall be considered significant, when one observes the absolute number of illiterates and the trends of the historical series of data, nor is possible attribute this reduction to the results of the public policies. By making a historical study, one can see that economic, political and social relations end up determining the conditions in which the supply of schooling will take place, what persons will have access to it, what will be its possibility of progress, among other aspects. At the same time, educational structures have been at the mercy of the social and economic context, failing to seek an organization that could offers real development opportunities to all students.

KEYWORDS: Illiteracy; Literacy; Literacy Public Policies.

\section{Introdução}

O Brasil possui um elevado número de pessoas com idade acima de 15 anos que não sabem ler e escrever. Utilizando dados (IBGE, 2015) da Pesquisa Nacional por Amostra de Domicílios (Pnad), realizada pelo Instituto Brasileiro de Geografia e Estatística (IBGE) estima-se que em 2015 cerca de 8\% da população seja analfabeta (12,9 milhões de pessoas). Esse índice de analfabetismo varia bastante conforme a região geográfica, indo de $16,2 \%$ no Nordeste para cerca de $4 \%$ no Sudeste e no Sul, e também por idade, com uma taxa de $0,8 \%$ entre jovens de 15 a 19 anos e de 22,3\% entre pessoas com 60 anos ou mais. Também há diferença significativa entre brancos $(5 \%$ de analfabetos) e pretos $(11,2 \%)$. Os dados indicam uma evidente correlação entre as taxas de analfabetismo e as situações de pobreza, exclusão e baixo desenvolvimento econômico. Os dados levantados pelo IBGE comprovam ainda que a Meta 9 do Plano Nacional de Educação (PNE), que previa para este ano de 2016 uma redução do analfabetismo para 6,5\% da população, não foi cumprida, o que leva a um questionamento quanto às políticas públicas que vêm sendo implementadas para enfrentar esse problema.

O propósito do presente texto é contribuir para a compreensão das razões desse relativo fracasso na superação do analfabetismo, através do levantando de aspectos da história da educação e das lições que nosso passado pode fornecer para buscar novos caminhos nesse campo. Os dados e análises aqui apresentados resultaram da pesquisa de Mestrado de um dos autores (BRAGA, 2015).

Apesar da grave situação do analfabetismo no Brasil, especialmente se comparada à condição de outros países da América Latina, que já erradicaram o 
analfabetismo há décadas, existe uma percepção na sociedade atual e mesmo entre pesquisados não ligados ao tema, de que o analfabetismo vem diminuindo e sua eliminação é apenas uma 'questão de tempo'. Um dos fatores que explica essa visão distorcida é o uso recorrente de dados estatísticos que mostram apenas a evolução dos índices ou taxas de analfabetismo, cuja queda é amplamente divulgada pela mídia e comemorada pelos governos de ocasião. Um dado raramente exposto se refere ao número absoluto de analfabetos. Para comparar o resultado dessas duas informações, podemos verificar na Tabela 1 o declínio das taxas de analfabetismo ao longo dos decênios entre 1900 a 2010, na população da faixa etária acima de 15 anos, redução essa que se acentua entre as décadas de 1950 e 1960, com uma queda de 10,9 pontos percentuais. Os dados apontam uma forte redução percentual de analfabetos passando de 65,3\% em 1940 para 9,6\% no ano de 2010. No entanto, analisando o número absoluto de pessoas analfabetas percebe-se que de 1900 a 2010 esse número mais que dobrou e em 2010 havia aproximadamente a mesma quantidade absoluta de analfabetos que havia em 1940.

Tabela 1: Analfabetismo na faixa etária de 15 anos ou mais - Brasil 1900/2010

\begin{tabular}{r|r|r|r}
\hline \multirow{2}{*}{ Ano } & \multicolumn{3}{|c}{ População com 15 anos ou mais (em milhares) } \\
\cline { 2 - 4 } & \multicolumn{1}{|c|}{ Total $^{1}$} & Analfabeta $^{1}$ & \multicolumn{1}{c}{ Taxa de analfabetismo } \\
\hline 1900 & 9.728 & 6.348 & 65,3 \\
1920 & 17.564 & 11.409 & 65,0 \\
1940 & 23.648 & 13.269 & 56,1 \\
1950 & 30.188 & 15.272 & 50,6 \\
1960 & 40.233 & 15.964 & 39,7 \\
1970 & 53.633 & 18.100 & 33,7 \\
1980 & 74.600 & 19.356 & 25,9 \\
1991 & 94.891 & 18.682 & 19,7 \\
2000 & 119.533 & 16.295 & 13,6 \\
2010 & 144.814 & 13.933 & 9,6
\end{tabular}

Fonte: Elaboração própria com dados do Censo Demográfico do IBGE.

Conforme nos mostra a Figura 1, apenas começa a ocorrer uma queda no número total de pessoas analfabetas entre 15 anos e mais a partir da década de 1980.

Figura 1: Analfabetismo na faixa etária de 15 anos ou mais - Brasil 1900/2010 


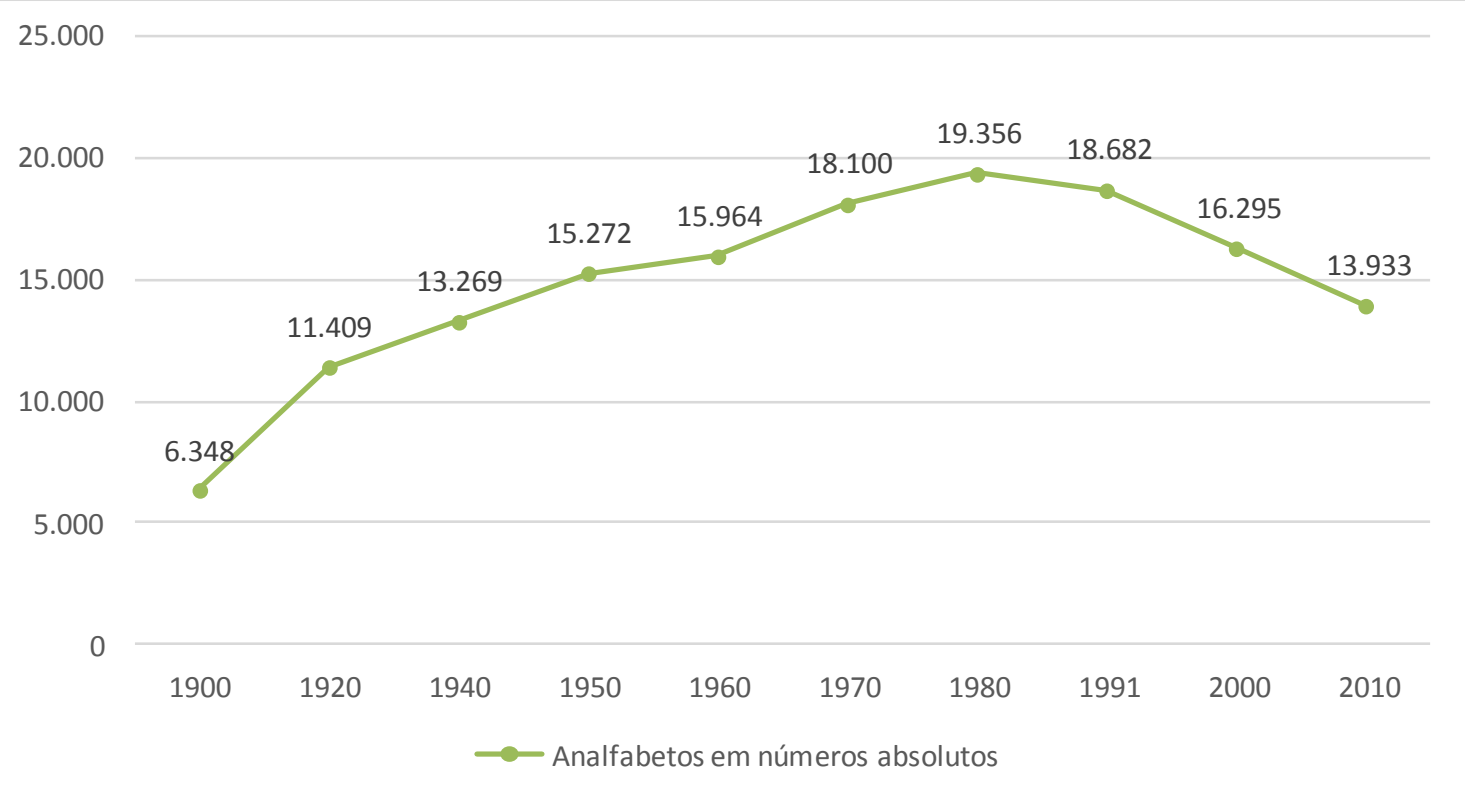

Fonte: Elaboração própria com dados do Censo Demográfico do IBGE.

A explicação para esse fenômeno não pode ser buscada apenas em fatores conjunturais e em políticas de governos específicos, mas precisa encontrar explicações nas grandes linhas estruturantes das relações sociais que marcam a história da educação e, em particular, da alfabetização e educação de jovens e adultos, desde a chegada dos portugueses ao Brasil.

$\mathrm{Na}$ realidade, foi da interação dos interesses externos com os interesses internos que resultou a formação social brasileira. Sob a ação dessa ordem de fatores, essa sociedade se transformou e vem se transformando, há quase cinco séculos. É uma existência marcada pela continuidade de alguns traços, que apenas se disfarçam numa face nova e, pela descontinuidade, que obriga o todo a se reorganizar para evitar mudanças radicais. Assim, atentando para os acontecimentos nacionais e internacionais e para os seus resultados transitórios ou mais permanentes em nossa sociedade, é que podemos entendê-la, para nela atuar com alguma desenvoltura (XAVIER; RIBEIRO; NORONHA, 1994, p. 28).

Os próximos tópicos irão abordar em linhas gerais as principais etapas do processo de desenvolvimento da educação no Brasil e seus reflexos no problema do analfabetismo.

\section{$O$ analfabetismo de jovens e adultos no período colonial}


É importante considerar que a educação dos povos nativos do Brasil pelos portugueses, esteve a serviço de um projeto de 'domesticação' e aculturação que visava a tornar a primitiva colônia um negócio lucrativo economicamente. Essa educação trazida pelos portugueses introduziu o Brasil no mundo da cultura ocidental "por meio de um processo envolvendo três aspectos intimamente articulados entre si: a colonização, a educação e a catequese" (SAVIANI, 2008, p.26). Dessa forma, procurouse ignorar e suprimir os processos educativos que já existiam entre as populações indígenas que aqui habitavam há milhares de anos:

Obviamente que, havendo população no território descoberto pelos portugueses, que viviam conforme uma determinada forma de organização social, a educação também se fazia presente nessas sociedades (SAVIANI, 2008, p. 35-36). [...] não havia instituições específicas organizadas tendo em vista atingir os fins da educação. Por isso a educação era espontânea. E cada integrante da tribo assimilava tudo o que era possível assimilar, o que configurava uma educação integral (SAVIANI, 2008, p. 38).

Diferente de outras populações nativas do continente americano, nossas comunidades indígenas não desenvolveram sistemas próprios de escrita. A primeira tentativa de alfabetização ocorreu por meio da Igreja Católica, quando da chegada dos padres jesuítas ao país. O ensino jesuítico dirigia o olhar para o entendimento das Sagradas Escrituras e baseava-se na leitura, na escrita e no cálculo. "Ter acesso aos catecismos, livros e cantos religiosos, realizar o complicado cálculo dos dias e das festas religiosas, entender e acompanhar ativamente os ritos e sacramentos era tudo o que se esperava da instrução do gentio" (XAVIER; RIBEIRO; NORONHA, 1994, p.43). Esse ensino foi encomendado pela Coroa Portuguesa e pelo Papado com a missão de incorporar os "selvagens" aos costumes portugueses através da fé Católica.

A principal estratégia utilizada para a organização do ensino, tendo em vista o objetivo de atrair os "gentios", foi agir sobre as crianças. Para isso se mandou vir de Lisboa meninos órfãos, para os quais foi fundado o Colégio dos meninos de Jesus de São Vicente. Pretendia-se pela mediação dos meninos brancos, atrair os meninos índios e, por meio deles, agir sobre seus pais, em especial os caciques, convertendo toda a tribo para a fé católica (SAVIANI, 2008, p. 43).

Saviani (2012) chama a instrução realizada de pedagógico-catequética, pois buscava incutir nos nativos a fé católica e os costumes portugueses. O ensino jesuítico era benéfico aos colonizadores, visto que "domesticava" os índios, civilizando-os e 
tornando-os mais fáceis de 'alhear', pois estavam mais dóceis e poderiam ser aproveitados como mão de obra escrava. A catequese era, portanto, o elemento central dos conteúdos dessa incipiente escolarização:

Há uma estreita simbiose entre educação e catequese na colonização do Brasil. Em verdade a emergência da educação como um fenômeno de aculturação tinha na catequese a sua idéia-força, o que fica claramente formulado no Regimento de Dom João III estatuído em 1549 e que continha as diretrizes a serem seguidas e implementadas na colônia brasileira pelo primeiro governo geral (SAVIANI, 2008, p. $31)$.

No intervalo de tempo entre 1549 a 1570, citam-se nas cartas de Nóbrega, principalmente na carta de 15 de junho de 1553 destinada ao padre Luís Gonçalves da Câmara, a abertura de escolas, onde indígenas e filhos de colonos eram instruídos para a prática da leitura e escrita, da língua portuguesa, do cristianismo, do canto orfeônico e música instrumental, do teatro e dança, do profissionalismo agrícola e de gramática, para aqueles mais capacitados. Com a morte de Nóbrega, desacreditados da ascensão educacional dos nativos, as escolas passaram a focar a educação apenas dos brancos, filhos dos colonos. (FREIRE, 1989, p.34).

Assim sendo, meio século após o início da 'domesticação’ indígena, as missões jesuíticas deram lugar ao novo sistema de ensino: os Seminários, estabelecidos inclusive com a intenção de formar novos sacerdotes.

Mantendo os ideais educacionais de Nóbrega, o padre Anchieta utilizava como estratégia o uso da linguagem Tupi para fazer-se compreender pelos nativos e também para relacionar-se com os colonos que já entendiam a língua materna tupinambá. Outro artifício largamente empregado em seus ensinamentos era a poesia e o teatro "cujo correlato imaginário é um mundo maniqueísta cindido entre forças em perpétua luta: Tupã-Deus, com sua constelação familiar de anjos e santos, e Anhangá-Demônio, com a sua corte de espíritos malévolos" (BOSI, 1992, p.67-68 apud SAVIANI, 2008, p. 46), mostrando assim uma das estratégias dos colonizadores que é o incentivo ao sincretismo religioso e cultural para o 'povo', paralelo a um ensino formal e sistemático para a 'elite'.

Dessa forma, a alfabetização de jovens e adultos, seja na sua própria língua materna, seja na língua portuguesa não se colocou como um objetivo das ações políticas desse período. O "pacto colonial" repercutiu inclusive em restrições de acesso a materiais de leitura/escrita e ao uso das línguas nativas, através de atos como: Proibição 
da língua 'brasílica' - Tupi (1727); Destruição da primeira gráfica da Colônia (1747); Proibição do despacho de livros e papéis para o Brasil (Alvará de 16 de dezembro de 1794); Aviso de repreensão a Câmara de Tamanduás (de 18 de junho de 1800, ao capitão-general de Minas) pelo ato de instituir uma aula de primeiras letras (FREIRE, 1989, p. 24-25).

Com a expulsão dos jesuítas pelo Marquês de Pombal, surge uma nova modalidade de ensino: as aulas régias, ou aulas avulsas, nas quais a responsabilidade pela educação passa da Igreja para o Estado. A partir de então decorreu um período de educação deficiente, durante o qual as escolas foram abandonadas e praticamente nenhum investimento foi efetuado. Foram 13 anos sem escolas, apenas com a inserção de aulas avulsas ministradas por professores em sua maioria arranjados; aulas estas rejeitadas pela população, já que não seguiam o modelo até então existente (religioso) e caracterizavam-se pela fragmentação dos conteúdos e disciplinas. A grande maioria dos habitantes permaneceu à margem de qualquer instrução formal e de acesso à leitura e à escrita.

No contexto das guerras napoleônicas no continente europeu, a Família Real e a Corte portuguesa decidem pela transferência para a colônia americana, de forma que a indispensável acomodação na capital brasileira, a cidade do Rio de Janeiro, impôs diversas mudanças, inclusive no campo intelectual e educacional, como a produção da Imprensa Régia, a Biblioteca Pública, o Jardim Botânico, o Museu Nacional, o primeiro jornal A Gazeta do Rio, a primeira revista As Variações ou Ensaios de Literatura, e a primeira revista carioca, $O$ Patriota. Foram criados também os cursos de cirurgia (BA), cirurgia e anatomia (RJ) e na sequência, o de medicina (RJ). Igualmente são criados cursos, visando à formação de mão de obra qualificada, como serralheiros, oficiais de lima, espingardeiros, economia, agricultura, dentre vários outros, todos girando em torno da economia das indústrias e da agricultura. Este desenvolvimento e mudanças ocorreram prioritariamente no Rio de Janeiro, onde a Corte se instalara (RIBEIRO, 2003).

\section{$O$ analfabetismo de jovens e adultos no Império}

Com a Independência do Brasil em 1822, fez-se necessária a elaboração e promulgação de uma Constituição, e esta foi outorgada em 1824. Esse documento 
aponta para a necessidade de universalização da "instrução primária", como aponta Ribeiro:

A inviolabilidade dos direitos civis e políticos dos cidadãos brasileiros, que tem por base a liberdade, a segurança individual e a propriedade, é garantida pela Constituição do Império, entre outras maneiras, pela 'instrução primária gratuita a todos os cidadãos' ( $\left.{ }^{\circ} 32\right)$ (RIBEIRO, 2003, p. 45).

A escolarização deveria atingir toda a nação, porém como ainda era uma sociedade escravocrata, isso não ocorreu, atingindo apenas os homens livres, mesmo porque com a crise econômica que se seguiu, a educação não era prioridade.

Posteriormente, mais especificamente na metade do século XIX, a educação brasileira apresenta déficit em sua qualidade e quantidade devido à insuficiência de recursos, mesmo para as escolas primárias. Faltavam recursos econômicos, metodológicos e de pessoal (principalmente por não ser uma profissão que estimulasse o interesse e por não existir nenhuma preparação específica), fazendo com que o atendimento à população fosse muito limitado.

A criação da primeira escola normal ocorreu no ano de 1835, em Niterói, e cinco anos após havia apenas quatorze alunos formados. Nos anos posteriores verificamos a criação dessas escolas em Minas Gerais, Bahia, São Paulo, Pará, Sergipe, Santa Catarina e Ceará, algumas delas não chegando nem a funcionar, ou então reabrindo várias vezes por falta de matrículas (FREIRE, 1989, p.48); inferindo-se a ausência de formação apropriada para a alfabetização.

A partir de 1850, o país inicia um processo de transição para se transformar em uma sociedade urbano-agrícola-comercial, o que foi decorrência das necessidades internas e, principalmente, da intenção dos países mais desenvolvidos de se expandirem através dos países periféricos, como o Brasil, para atuar no competitivo mercado capitalista. Com isso, algumas cidades passaram a ser movimentados polos do crescimento capitalista, provocando a reestruturação do sistema de trabalho urbano e atração sobre o contingente populacional de rendas altas, médias e baixas, escravos forros e libertos e prostituição (RIBEIRO, 2003, p. 53).

As modificações no desenvolvimento econômico possibilitaram ao país uma consolidação no contexto da época, o que se refletiu na área educacional, na qual se destacou a participação de homens notáveis como Couto Ferraz e sua Reforma. Este foi titulado como presidente da província do Rio de Janeiro em 1848 e exerceu essa função 
até 1853, quando se tornou ministro do Império. Foi nesse exercício que baixou o Decreto $\mathrm{n}^{\circ}$ 1.331-A, de 17 de fevereiro de 1854, regulamentando a reforma do ensino primário e secundário do município da Corte, documento este formado por cinco títulos. Neste documento verificamos temas ligados à educação primária, inspeção escolar e regulação das escolas particulares e da obrigatoriedade de ensino, dentre outros assuntos tratados. Encontramos neste documento traços do que podemos chamar de consolidação de um sistema nacional de ensino (SAVIANI, 2008).

Essa reforma, por sua vez, excluía boa parte da população ao estabelecer que "nas escolas públicas não seriam admitidos os que padecessem de moléstias contagiosas, os que não tivessem sido vacinados (...), e os escravos (Art. 69)". Em relação à alfabetização de jovens e adultos, ainda que o decreto previsse a "instrução para adultos" (Art. 71), ficava dependendo da disponibilidade dos professores, de modo que dificilmente se viabilizava esse tipo de estudos (FREIRE, 1989, p.92).

É possível constatar, portanto, que a instrução primária das crianças, embora fosse constitucionalmente destinada a todas elas, já previa uma exclusão formal da população indígena, escrava e de uma parte das mulheres, originando consequentemente um grande número de pessoas analfabetas, sem que existissem outras ações para alfabetizar essa população, o que estava em consonância com a estrutura agrárioexportadora e escravista do sistema.

Apesar da Independência brasileira, preservou-se o modelo colonial de inserção internacional, com a produção para o mercado externo focada na agricultura, na pecuária e no extrativismo, aproveitando os fartos recursos naturais e a abundância de mão de obra de baixo custo. Além do café, o Brasil passou a comercializar a borracha, o cacau e o gado. Já o mercado interno era abastecido por pequenos agricultores que não competiam com os produtos que os grandes latifundiários exportavam. Para essa forma de inserção não se gerava uma demanda de expansão do conhecimento elaborado e do uso da linguagem escrita. Segundo informações contidas no Tomo I de Rui Barbosa (1947, 16-7), o Brasil no ano de 1876 possuía uma população livre contabilizada em 8.419.672 habitantes, com um total de 5.579.945 analfabetos (excluindo os menores de 5 anos), ou seja 78,11\% da população era analfabeta (apud FREIRE, 1989, p. 116).

Em 1878 foram criados cursos de alfabetização de adultos (instrução primária), destinados aos homens analfabetos com idade superior a quatorze anos na condição de libertos ou livres, através do Decreto $\mathrm{n}^{\circ}$ 7.031-A de 6 de setembro, no qual visivelmente há uma "preocupação em impor dificuldades em lugar de facilitar a proposta que diz 
querer atingir de alfabetização" (FREIRE, 1989, p. 96). Nos artigos estavam previstas regras disciplinares rígidas com um sistema de punições e recompensas, aulas diárias com duração de apenas duas ou três horas (a duração estava diretamente relacionada com a estação do ano: duas horas no verão e três horas no inverno). Ao final do curso o aluno era submetido a uma prova escrita (apenas 30 minutos de duração) com o conteúdo lecionado durante o decorrer de todo o ano, uma prova oral pública e banca examinadora que aprovaria ou reprovaria o aluno através de votos e "ainda não terminou a gincana de obstáculos para derrubar os adultos analfabetos: no julgamento dos exames, seriam levadas em conta, além das provas orais e escritas, as notas de aplicação e comportamento que o professor apresentava à comissão julgadora" (FREIRE, 1989, p.97 - grifos no original). Como se pode perceber, a disponibilidade legal da educação de jovens e adultos foi carregada de empecilhos e incentivos à desistência.

Neste período encontramos também a criação de escolas protestantes, como reflexo do arrefecimento da relação Estado - Igreja, levando à população não católica a possibilidade de estudar. Dessa forma, nota-se o surgimento de um dos traços que irão marcar, até os dias atuais, muitas iniciativas de alfabetização de jovens e adultos: na ausência de uma atuação efetiva do Estado, surgem ações em conduzidas por instituições de caráter religioso, conferindo ao ensino para jovens e adultos uma dimensão muitas vezes assistencialista (ligada à ideia de caridade cristã).

Outro traço que se delineia com clareza nesse período são as reformas educacionais que se anunciam com grandiosas intenções, mas na prática não definem formas concretas de realização dos objetivos proclamados. Exemplo desse caso é a reforma de Leôncio de Carvalho, Decreto $\mathrm{n}^{\mathrm{o}} 7.247$ de 19 de abril de 1879, que estabeleceu a criação de jardins de infância para meninos e meninas entre três a sete anos de idade, em cidades do distrito do município da Corte, caixa escolar, bibliotecas e museus escolares, definiu diretrizes para as Escolas Normais com estabelecimento de currículo, designação de docentes e remuneração dos funcionários. A reforma era composta por um longo documento com 29 artigos, contendo 174 itens ao decorrer destes (SAVIANI, 2008).

Na prática, o Estado brasileiro se desobrigava de oferecer a educação escolar a toda a população, pois a reforma estabelecia em seu primeiro artigo, ser: “completamente livre o ensino primário e secundário no município da Corte e o superior 
em todo o Império, salva a inspeção necessária para garantir as condições de moralidade e higiene" (SAVIANI, 2008, p. 136).

Duas correntes filosóficas influenciaram o cenário político-econômico nesse período final da monarquia: o Liberalismo e o Positivismo. Encontramos a influência do liberalismo desde o período colonial, presente na Constituição de 1824; “críticos do "absolutismo" político brasileiro, se empenharam na abolição do trabalho escravo, na representação eleitoral mais ampla e com renovação dos mandatos (...) e na liberdade de consciência" (FREIRE, 1989, p.73); o ideal Positivista, utilizado como estratégia de modernização, pautava-se em três eixos: família, pátria e humanidade, e seus adeptos “tencionavam implantar no Brasil a 'ditadura do progresso' (...) através de uma república científico-industrial, na qual a fé seria depositada na Ciência, a ordem material seria a única condição de progresso" (FREIRE, 1989, p. 71), dando origem ao lema positivista em nossa bandeira. O lema: Ordem e Progresso traduzia (traduz?) perfeitamente os interesses do de um setor das classes dominantes, preocupado em conduzir o Brasil na transição econômica do modelo escravista ao assalariado.

Nesse contexto, "o positivismo se adequava às condições morais, intelectuais, sociais, políticas e econômicas do Brasil, daí sua disseminação e eficácia em perpetuar estas mesmas condições que o puderam abarcar e receber" (FREIRE, 1989, p.73). Ao se apropriar dessas duas vertentes ideológicas (liberalismo e positivismo), o setor da classe dominante que estava em ascensão buscou instituir no Brasil um regime político mais adequado aos seus interesses. A monarquia já não se adaptava a esse contexto. "O aparelho do Estado se tornara obsoleto, não correspondia mais à realidade política e econômica, transformara-se num trambolho" (SODRÉ, 1979, p. 292 apud FREIRE, 1989, p.74). Com a perda de poder dos nobres açucareiros (através de um golpe de Estado arrematado pelo exército) e a ascensão dos republicanos cafeicultores, instituiuse a República no Brasil, seguida da promulgação da Constituição Republicana de 1891, que garantiria a permanência do poder nas mãos dos detentores do capital (FREIRE, 1989, p.74).

\section{$O$ analfabetismo de jovens e adultos no período republicano}

Do Império para República, inicialmente a situação educacional não sofreu grandes modificações, embora, como de praxe, fossem anunciadas grandes mudanças e transformações que não resultavam em consequências efetivas na prática. 
Rotulando a população analfabeta como incapaz, a Constituição Republicana de 1891 suprimiu o critério eleitoral de renda, porém conservou a restrição de voto ao analfabeto. Ao contrário do que deveria ter ocorrido, o poder público não se interessou no alargamento do sistema escolar (XAVIER; RIBEIRO; NORONHA, 1994, p. 103). Possuindo "aproximadamente, $85 \%$ de analfabetos, excluí-los do processo eleitoral (...) era também diminuir intencionalmente o número de eleitores (e sua qualidade também) e, assim, perpetuar a sociedade de direitos e privilégios de muito poucos" (FREIRE, 1989, p.163). Ou seja, deixar de lado nas eleições a massa analfabeta, significou abafar reivindicações por direitos do povo economicamente excluído, das camadas populares, possibilitando eleger tão somente representantes dos interesses dominantes.

Neste contexto político, que se instalou com a República, as divisões das atribuições educacionais permaneceram como no período imperial. Consequentemente, também se manteve a precariedade do ensino, tanto na dimensão quantitativa, quanto na qualitativa. Neste período a região Sudeste, palco da produção cafeeira e da industrialização incipiente que ela possibilitou, já apresentava melhores condições econômicas de extensão da instrução pública e demandava uma expansão do conhecimento e maior qualificação da mão de obra. Contrariamente, no Norte e Nordeste a instrução pública não se fazia necessária às elites, já que a população dessas duas regiões era basicamente formada por camponeses, estes eram submissos aos donos das terras e do poder local, os coronéis (XAVIER; RIBEIRO; NORONHA, 1994, p. $105)$.

A partir da década de 1910, ocorreram transformações econômico-sociais, com a decadência do café brasileiro no mercado internacional. Reivindicando a democratização do regime político e do sistema escolar, a classe média, influenciada pelas doutrinas liberais estava insatisfeita por não se sentir beneficiada pela 'ordem e progresso'. Também começam a surgir movimentos de contestação ao capitalismo, de cunho anarquista e socialista. Esses setores defendiam o ensino popular com caráter de "escola única, universal e gratuita". Porém este movimento foi neutralizado na década seguinte, quando as camadas populares cederam aos encantos das ideias liberais e ao brilho ilusório da ascensão social através da industrialização (XAVIER; RIBEIRO; NORONHA, 1994, p. 116-118).

Xavier; Ribeiro; Noronha (1994), ao falarem da influência dos líderes socialistas na educação na década de 1910, ressaltam que estes verificaram que o analfabetismo era um obstáculo na propagação de seus ideais de justiça, igualdade e distribuição de 
riqueza, já que os analfabetos poderiam não entender as divulgações realizadas. Defendiam o ensino obrigatório, gratuito e técnico-profissional, além da manutenção das escolas públicas, laicidade da educação escolar e combate ao ensino religioso. Conseguiram a criação de Escolas Operárias e de Bibliotecas Populares e, para efetivarem o desejo de mudanças, defendiam que os recursos para essas iniciativas deveriam ser levantados entre os próprios trabalhadores, ao mesmo tempo em que disputavam com a Igreja Católica os recursos públicos destinados à educação e ao assistencialismo (p. 134-135).

Houve também neste período a influência dos anarquistas, que assim como os socialistas, entendiam o analfabetismo como obstáculo para transformar a sociedade, mudança que consistia em formar homens livres e solidários, e para isso eram necessárias iniciativas culturais e educacionais. Diferentemente dos socialistas, não lutavam pelo ensino obrigatório e consideravam a Igreja e o Estado como mantenedores do capitalismo e para combater esse ensino, empenhavam-se na criação de escolas que não tivessem ligações com a Igreja ou o Estado, mas que fossem mantidas com recursos dos interessados (XAVIER; RIBEIRO; NORONHA, 1994, p. 106).

Em resposta às mobilizações populares, foi criada em 1915 a Liga Brasileira Contra o Analfabetismo, regulamentada em 7 de setembro com o lema: "Combater o analfabetismo é dever de honra de todo brasileiro". A Liga lutou pela obrigatoriedade do ensino primário e pelo objetivo de alcançar um país sem analfabetos em 7 anos, ou seja, lançou a meta de chegar ao centenário da Independência livre do analfabetismo. Freire (1989) explica que os grandes avanços desta campanha contra o analfabetismo se deram mais em termos qualitativos do que quantitativos, fazendo com que o debate em torno do analfabetismo adquirisse grande importância entre a população brasileira. Quanto aos resultados, a redução foi um decréscimo anual de 5\%, conseguindo atingir em 1921 uma taxa de $65 \%$ de analfabetos.

Os comunistas também não ficaram de fora dos ideais de mudanças na área educacional. Em 1922 criaram o Partido Comunista do Brasil - PCdoB e traçaram um plano educacional, em que se podem relevar os seguintes pontos: expansão do ensino público gratuito, obrigatório e laico; fornecimento às crianças que necessitavam apoio financeiro através de material escolar, roupa, comida e transporte; expansão das escolas profissionais, como complemento e continuação da escola primária; melhores condições aos professores; e, auxílio às bibliotecas operárias e populares (XAVIER; RIBEIRO; NORONHA, 1994, p. 139). 
Em 1924 foi criada a Associação Brasileira de Educação - ABE liderada por Heitor Lyra da Silva, onde pessoas da sociedade civil interessadas pela educação se reuniram pela primeira vez, com a reunião de 13 intelectuais cariocas. Sem cunho filosófico, religioso ou político, “embora na origem o grupo tivesse a intenção de organizar um 'partido de ensino', a ABE firmou-se como órgão apolítico, destinado a congregar todos os interessados na causa da educação" (SAVIANI, 2008, p.229). A $\mathrm{ABE}$ deu corpo para os movimentos dos renovadores, através das conferências, que posteriormente atingiram grande abrangência.

Foram realizadas três conferências, entre os anos de 1927 e 1929, voltadas para interesses educacionais. Porém, houve um fracasso na implementação das propostas apresentadas, e “nem o 'otimismo pedagógico' nem o 'entusiasmo pela educação', entendidos como contra-ataques dos dominantes, tiveram condições de mudar substantivamente a educação primária no Brasil" (FREIRE, 1989, p. 219). As taxas de analfabetismo continuavam altas: no ano de 1920, considerando adultos e jovens acima de 15 anos, possuíamos aproximadamente $65 \%$ de analfabetos e em duas décadas ocorre uma lenta redução fazendo com que se atingisse 56,22\% em 1940.

Dentre as décadas de 1910 a 1960, observa-se que houve um aumento contínuo na organização escolar, em seus três níveis. $\mathrm{O}$ aumento se deu também na evasão e repetência escolar. Os números mostram que em 1935, 54\% das crianças estavam fora da escola; já em 1955 eram 26\%. Porém, as crianças excluídas da escola em 1935 eram pouco mais de 5 milhões e em 1955 passavam de 6 milhões. A cada "[...] cem crianças que conseguem entrar na primeira série do ensino elementar, existem apenas $13 \mathrm{em}$ 1935 ou 21 em 1955 que conseguem concluir a quarta série desse mesmo ensino" (XAVIER; RIBEIRO; NORONHA, 1994, p. 161). Quanto à reprovação o quadro é o mesmo: quando se trata de porcentagem, encontram-se resultados melhores em razão do crescimento populacional, porém em números absolutos verifica-se que houve aumento constante.

A análise da situação do ensino elementar permite considerar como são estreitos os horizontes culturais tanto das antigas frações da classe dominante como das novas, que vão tendo sua importância aumentada no processo de desenvolvimento em curso na sociedade brasileira dos anos 10 aos anos 60 (XAVIER; RIBEIRO; NORONHA, 1994, p.163).

A discriminação existente aos menos favorecidos é tão grande, que na “Constituição de 1937 (Art. 129) que diz que o ensino profissional é destinado às 
classes menos favorecidas. É, pois, uma discriminação declarada em lei” (XAVIER; RIBEIRO; NORONHA, 1994, p. 164).

No setor econômico e político, o período entre 1930 e 1964 é marcado pelo governo de Getúlio Vargas e a tentativa de implantação de um modelo nacionaldesenvolvimentista industrial baseado na substituição de importações e fortalecimento do mercado interno. Esse modelo entra em conflito com a entrada crescente de capital internacional no país, levando a uma crise do ideário nacionalista. $\mathrm{O}$ aprofundamento dessa crise gerou uma ruptura do modelo político, levando inicialmente ao suicídio de Getúlio e posteriormente ao golpe militar de 1964.

No período que compreende 1958 a 1964, a sociedade ficou marcada por diversos programas sociais e mobilizações populares que possuíam como interesse a alfabetização de jovens e adultos. Ferraro (2009) considera que nesse período houve uma nova concepção sobre o analfabetismo devido à urbanização e industrialização, além de novas concepções pedagógicas de alfabetização, e cita movimentos de alfabetização ocorridos neste período: Experiência da Rádio-escola, no Rio Grande do Norte (1958), Campanha Nacional de Erradicação do Analfabetismo - CNEA (1958), Campanha de Educação de Adolescentes e Adultos - CEAA (1958), Movimento de Cultura Popular -MCP (1960), o surgimento do Método Paulo Freire (1961), Movimento de Educação de Base - MEB (1961), Campanha Pé no Chão também se Aprende a Ler (1961), e em 1963 houve a experiência de alfabetização do educador Paulo Freire em Angicos/RN.

Essa onda de mobilizações populares e campanhas de alfabetização estavam estritamente relacionadas com os embates eleitorais, "o direito ao voto, contudo, estava condicionado à alfabetização, o que levou os governantes a organizar programas, campanhas e movimentos de alfabetização de jovens e adultos" (SAVIANI, 2008, p. 316), abrangendo a população urbana e rural. Esses movimentos conhecidos como Movimentos de Educação Popular, possuem caráter de conscientização política da população, “a expressão 'educação popular' assume, então, o sentido de uma educação do povo, pelo povo e para o povo" [...] e apesar de apresentarem distinção entre si [...] "esses movimentos tinham em comum o objetivo da transformação das estruturas sociais e, valorizando a cultura do povo como sendo a autêntica cultura nacional" (SAVIANI, 2008, p. 318).

Em 1961, no governo de João Goulart, foi publicada a primeira LDB através da Lei $\mathrm{n}^{\circ} 4.024$ de 20 de dezembro, entrando em vigor a partir de 1962, como decorrência 
dessa lei foi criado o Conselho Federal de Educação - CFE, com a participação de Anísio Teixeira que coordenou a criação do Plano Nacional de Educação (PNE), que tinha entre seus objetivos erradicar o analfabetismo. Essas e outras iniciativas de alfabetização foram interrompidas pela Ditadura Militar, sendo seus principais líderes e representantes presos e exilados. "Mas o governo militar não se contentou em acabar com os movimentos políticos de alfabetização e cultura popular. Entendeu que precisava provar que a alfabetização era e devia ser tratada como uma questão apenas técnica, de método" (FERRARO, 2009, p.98 - grifos no original)

Desencadeado o golpe militar em março de 1964 e consumado no dia 1 de abril, ocorreu um rompimento com o modelo político implantado, porém, não houve uma mudança do modelo econômico.

\begin{abstract}
Não tendo havido ruptura, mas continuidade no plano socioeconômico, compreende-se que tenha havido continuidade também na educação. E isso se refletiu na legislação que instituiu as reformas de ensino baixadas pela ditadura. Eis por que não foi necessário revogar os primeiros títulos da LDB (Lei n. 4.024, de 20 de dezembro de 1961), exatamente os títulos que enunciavam as diretrizes a serem seguidas. Foram alteradas as bases organizacionais, tendo em vista ajustar a educação aos reclamos postos pelo modelo econômico do capitalismo de mercado associado dependente, articulado com a doutrina da interdependência (SAVIANI, 2008, p.364).
\end{abstract}

Em 1964, através do decreto $\mathrm{n}^{\circ} 53.886$, o PNE foi extinto e substituído pela Cruzada de Ação Básica Cristã. Nos anos 1970 surgiu o MOBRAL - Movimento Brasileiro de Alfabetização, que somado a Cruzada de Ação Básica Cristã constituía em uma ferramenta de controle político das massas (XAVIER; RIBEIRO; NORONHA, 1994).

Segundo Noronha (XAVIER; RIBEIRO; NORONHA, 1994), as metas nacionais do novo governo implantado resumiam-se em "altas taxas de acumulação, supremacia do grande capital e contenção dos trabalhadores" (p. 225). Com caráter explicitamente autoritário, o novo governo excluiu tudo o que fazia parte da "esquerda", extinguiu os partidos existentes e cassou os representantes políticos. As políticas públicas de alfabetização de jovens e adultos se reduziram a Campanhas e ao MOBRAL. Os resultados, no entanto, foram pífios:

No que se refere ao analfabetismo, por exemplo, o problema se agravou por dois motivos básicos: primeiro, porque o número de 
pessoas analfabetas (em números absolutos) aumentou e, segundo, porque não foram tomadas medidas efetivas em nível governamental para a superação desse problema. As medidas tomadas foram reduzidas a campanhas fragmentárias e sem continuidade (XAVIER; RIBEIRO; NORONHA, 1994, p. 227).

Com a rápida industrialização e internacionalização da economia a educação passou a ser voltada para atender à demanda das empresas por qualificação de mão de obra. Portanto, as reformas institucionais que eram implantadas referiam-se à escolarização/qualificação da população para torná-la mais eficiente e atender às demandas de modernização, objetivando formar um trabalhador obediente e que correspondesse ao exigido pelo mercado de trabalho. "A meta final a ser atingida, então, era a de viabilização do ideal de Brasil-Potência. E para se chegar a essa meta, a educação passou a ter destaque como fator de desenvolvimento" (XAVIER; RIBEIRO; NORONHA, 1994, p. 229).

Durante o governo de Castelo Branco (1964-1967), críticas ao analfabetismo e defesa da obrigatoriedade, gratuidade e universalização do ensino foram os temas que nortearam as diretrizes educacionais. Nos governos de Costa e Silva, Médici e Geisel as prioridades ficaram com a formação superior para as ocupações da tecnoburocracia estatal (XAVIER; RIBEIRO; NORONHA, 1994, p. 230-231).

“O aprofundamento das relações capitalistas decorrente da opção pelo modelo associado-dependente trouxe consigo o entendimento de que a educação jogava um papel importante no desenvolvimento e consolidação dessas relações" (SAVIANI, 2008, p. 365). Surge então a "concepção produtivista de educação", assentada no Tecnicismo.

No longo período da ditadura, foi definido como o principal objetivo relacionado ao analfabetismo "eliminar, possivelmente, no decorrer da década de 1970, o analfabetismo de adolescentes e adultos, com esforço concentrado na faixa etária dos 15 aos 35 anos de idade" (BRASIL, MEC, 1971, p.25-26 apud FERRARO, 2009, p.106). A obrigatoriedade de ensino se estendeu para as crianças de 7 a 14 anos e o ensino fundamental expandiu para oito anos. Ferraro (2009) aponta, no que se refere ao prolongamento dos anos de estudo e de sua obrigatoriedade, que essas medidas foram tomadas sem que o Estado se incumbisse de oferecer escola gratuita para toda a população e foram acompanhadas da liberação de ingresso no mercado de trabalho aos 12 anos, “[...] na conjuntura, do ponto de vista da expansão e acumulação do capital, 
interessava mais a sobrevivência física do que a educação dessa força suplementar de trabalho" (p.107).

Com o golpe militar em 1964, o Brasil passou por um período de repressão e autoritarismo, em que a liberdade de expressão não estava presente, bem como os direitos políticos das maiorias, “o lema positivista 'Ordem e Progresso' inscrito na bandeira do Brasil metamorfoseou-se em "segurança e desenvolvimento"” (SAVIANI, 2008, p. 367). Foi apenas em 1985 que chegou ao fim o governo ditatorial militar no Brasil, deixando um legado de crise econômica, social e política.

Saviani (2008) retrata a posição educacional do final da década de 1980, em que, devido às circunstâncias, as correntes pedagógicas de 'esquerda' apresentavam dificuldades crescentes. Era o momento de ascensão da democracia, resultado de um grande movimento político. E, apesar deste período ser conhecido como a 'década perdida', quando é considerada a organização educacional é reconhecida como "uma das mais fecundas de nossa história" (p.402).

Algumas criações marcaram esta década, como a Associação Nacional de PósGraduação e Pesquisa em Educação - ANPED em 1977, o Centro de Estudos Educação e Sociedade - CEDES em 1978, a Associação Nacional de Educação - ANDE em 1979, além da criação de associações, que posteriormente, através da Constituição de 1988 que cancelou a restrição de sindicalização, se transformaram em sindicatos, o que possibilitou a união de professores dos três níveis de ensino em âmbito nacional. Esse processo resultou em um 'movimento organizativo-sindical' que teve duas vertentes, a primeira era marcada "pela preocupação com o significado social e político da educação, do qual decorre a busca de uma escola pública de qualidade, aberta a toda a população e voltada precipuamente para as necessidades da maioria" e a segunda é marcada "pela preocupação com o aspecto econômico-corporativo, de caráter reivindicativo, cuja expressão mais saliente é dada pelo fenômeno das greves" (SAVIANI, 2008, 402-404).

Tais movimentos não obtiveram os resultados esperados em âmbito nacional, nesse momento, já que "o setor governamental teria sido marcado, no período, pela escassez e, até mesmo, pela ausência de medidas tendentes a resolver os graves problemas reiteradamente diagnosticados, denunciados e equacionados", porém em âmbito municipal e estadual algumas ações foram relevantes (SAVIANI, 2008, p. 406). 
Em âmbito estadual, diversos governos de oposição ao regime militar, eleitos em 1982, ensaiaram medidas de política educacional de interesse popular, destacando-se: 1. Minas Gerais, com o Congresso Mineiro de Educação, o combate ao clientelismo e a desmontagem do privatismo, colocando a educação escolar pública no centro das discussões; 2. São Paulo, com a implantação do ciclo básico, o estatuto do magistério, a criação dos conselhos de escola e a reforma curricular; 3. Paraná, com os regimentos escolares e as eleições para diretores; 4. Rio de Janeiro, com os Centros Integrados de educação Pública (CIEPS), apesar de seu caráter controvertido; 5. Santa Catarina, onde a oposição não conquistou o governo do estado, mas realizou um congresso estadual de educação que permeou todas as instâncias político-administrativas da educação catarinense (SAVIANI, 2008, p. 406-407).

Apesar da característica de descontinuidade e cheios de dificuldades, esses movimentos foram considerados como grandes ganhos para uma década tão conturbada.

Na década de 1990 mantém-se a crença na contribuição da educação para o processo econômico-produtivo, com o ensino voltado para a preparação da mão de obra, a educação voltada para a competitividade das empresas e a garantia de emprego no competitivo mercado de trabalho pela aquisição de 'capital humano' ou 'empregabilidade'. Com isso, especialistas passam a conceber os estudos como investimento individual e familiar em busca de habilidades para a corrida pelos empregos disponíveis. Entretanto, esse investimento não se mostra suficiente para a garantia de emprego "pelo simples fato de que, na forma atual do desenvolvimento capitalista, não há emprego para todos: a economia pode crescer convivendo com altas taxas de desemprego e com grandes contingentes populacionais excluídos do processo" (SAVIANI, 2012, p.96-97).

Desse modo firma-se uma pedagogia da exclusão, onde o trabalhador corre atrás de uma especialização para que assim possa se inserir no mercado de trabalho, e caso isso não ocorra, sente-se responsável por sua própria exclusão.

A hegemonia neoliberal caracteriza o final do século XX nos países capitalistas e as agências internacionais passaram a ditar as regras econômicas e políticas, como o FMI - Fundo Monetário Internacional, o BIRD - Banco Mundial, o OCDE Organização de Cooperação e Desenvolvimento Econômico. A América Latina recebeu a imposição neoliberal do "Consenso de Washington", que os países com empréstimos financeiros deveriam acatar e foram implementadas no Brasil no governo pelos governos: Fernando Collor de Mello (1990-1992), Itamar Franco (1992-1994) e Fernando Henrique Cardoso (1995-2002). Esse consenso consistia em uma listagem de 
regras a seguir, como: ajuste fiscal, redução do tamanho do Estado, privatizações de empresas estatais, abertura comercial, fim dos controles tributários que impediam a livre circulação do capital financeiro, reestruturação dos sistemas previdenciários, fiscalização e controle mais rígido dos gastos públicos, estabilidade monetária (FERREIRA JR, 2010, p.108).

Como consequência das medidas implantadas, em especial das privatizações e ajustes fiscais, as políticas públicas educacionais foram prejudicadas com o crescimento do ensino privado e deterioração das condições de trabalho na escola pública, deixando o ensino ainda mais ineficaz, especialmente em termos de qualidade. No ano de 2000, dos 30 milhões de alunos matriculados na escola pública no ensino fundamental, cerca de 3 milhões foram reprovadas e o restante das crianças eram "submetidas a um processo educacional miserável do ponto de vista do capital cultural clássico historicamente acumulado pela humanidade, [...] coroando um século de reformas malsucedidas e de políticas educacionais ineficientes" (FERREIRA JR, 2010, p. 109).

Durante o governo Fernando Henrique Cardoso, as reformas educacionais implantadas referem-se principalmente "à organização escolar, à redefinição dos currículos, à avaliação, à gestão e ao seu financiamento. Especialmente na educação básica, as mudanças realizadas redefiniram sua estrutura”, modificações essas postuladas através da Lei no 9.394 de 1996, a LDB - Lei de Diretrizes e Bases da Educação Nacional (OLIVEIRA, 2009, p. 199-200).

O quadro de uma educação pública ineficiente mostra que no ano de 2000 o Brasil acumulava 16 milhões de analfabetos dentro da população de 15 anos ou mais (IBGE, 2010) o que equivalia a 13,6\% da população nesta faixa etária, um índice de analfabetismo funcional de $27,3 \%$ (IBGE, 2001) e taxas de abandono escolar de $12 \%$ no ensino fundamental e 16,6\% no ensino médio (IBGE, 2000), e com apenas 45,9\% de docentes com nível superior no ensino fundamental, enquanto a rede privada possuía $62,5 \%$ (IBGE, 2000).

No ano de 2003, assume a Presidência da República Luis Inácio Lula da Silva (2003-2010), com o lema "Brasil, um país de todos" promovendo um conjunto de políticas públicas sociais e educacionais. Esse governo é marcado pelo crescimento econômico, refletido na queda dos índices de desemprego, que em 2003 era de 11,3\% e em 2010 caiu para 6,1\%, considerado o menor índice da história do país até então, e com a queda dos índices de pobreza extrema que foi reduzida de 11,49\% em 2005 para 7,28\% em 2009. Da mesma forma, os índices de pobreza caíram de 30,82\% em 2005 
para 21,42\% em 2009. Vários são os fatores envolvidos para a queda do índice de pobreza, entre eles está o crescimento econômico, a ampliação do mercado de trabalho e a implantação de políticas públicas voltadas para este público, como o Programa Bolsa Família (CURADO, 2011) e o crescimento real do salário mínimo e da massa salarial em geral. Podemos destacar como principal política pública de erradicação do analfabetismo o Programa Brasil Alfabetizado, implantado a partir de 2005. Mesmo tempo alguns aspectos positivos, esse Programa não gerou alterações significativas nas tendências em relação ao analfabetismo. No período de 2005 a 2015, o número de analfabetos diminuiu em cerca de 2,5 milhões, uma média de 250 mil por ano. Nesse ritmo, para alfabetizar o total de 12,9 milhões de analfabetos existentes atualmente, serão necessários cerca de 50 anos.

\section{Considerações finais}

Periodicamente são lançados Planos, Programas, Campanhas e outras iniciativas governamentais ou da sociedade civil com o propósito de "erradicar" o analfabetismo no Brasil. No entanto, não de discutem nem se apontam suas causas principais: de um lado, o modelo econômico baseado na produção de "commodities" para exportação, que demanda mão de obra pouco qualificada e baixo desenvolvimento científico e tecnológico. De outro lado, a precariedade do sistema educacional (ou a ausência dele), em especial no que se refere à alfabetização e educação e jovens e adultos. A alfabetização de adultos no Brasil, em pleno século XXI, ainda é tratada como ação assistencialista, deixada a cargo de professores voluntários, que recebem uma "bolsa" de $\mathrm{R} \$ 400,00$ no âmbito do Programa Brasil Alfabetizado e atuam em salas de aula com parcos ou inexistentes recursos pedagógicos. Tal programa não está inserido no processo formal de escolarização, o que resulta em descontinuidade após o término do curso. Quase tudo se passa na alfabetização de adultos sob o signo dessa precariedade estrutural.

Como imaginar que essa combinação de um ambiente socioeconômico desestimulante para os estudos, com um ambiente escolar precário possa resultar em resultados sólidos e avanços significativos? O quadro só não é pior pela dedicação abnegada de professores e alunos, que conseguem superar os obstáculos e as condições adversas e ainda assim obter resultados positivos, embora limitados. 
No entanto, se, em algum momento futuro de sua história, o Brasil quiser de fato se tornar um país desenvolvido do ponto de vista social, econômico, político e cultural, mesmo que dentro dos estreitos limites impostos pelo sistema capitalista, será preciso enfrentar o problema do analfabetismo entre jovens e adultos de forma bastante diferente do que sido feito até agora. Oxalá isso ocorra antes que a geração de pessoas com mais de 60 anos, que hoje representam 1 em cada 5 analfabetos, acabe morrendo sem ter adquirido esse bem cultural imprescindível para a vida moderna, cujo acesso vem sendo proclamado como um direito e anunciado como um dever do Estado por leis, reformas e programas há mais de um século.

\section{Referências}

BRAGA, A. C. O desafio da erradicação do analfabetismo no Brasil: uma análise do programa Brasil alfabetizado no município de Araraquara/SP. 2015. 114f. Dissertação (Mestrado) - Educação Escolar, Universidade Estadual Paulista "Júlio de Mesquita Filho", Araraquara, 2015.

CURADO, M. Uma avaliação da economia brasileira no governo Lula. Revista Economia \& Tecnologia. Ano 07, V. Especial, 2011. Disponível em: <http://www.economiaetecnologia.ufpr.br/revista/Especial Capa/Marcelo Curado.pdf > Aceso em: 15 dez. 2014.

FERRARO, A. R. História inacabada do analfabetismo no Brasil. São Paulo. Cortez, 2009. (Biblioteca básica da história da educação brasileira)

FERREIRA JR., A. História da educação brasileira: da colônia ao século XX. São Carlos: EdUFSCar, 2010. (Coleção UAB-UFSCar).

FREIRE, A. M. A. Analfabetismo no Brasil: da ideologia da interdição do corpo à ideologia nacionalista, ou de como deixar sem ler e escrever desde as Catarinas (Paraguaçu), Filipinas, Madalenas, Anas, Genebras, Apolônias e Grácias até os Severinos. São Paulo: Cortez: Brasília, DF: INEP, 1989. (Biblioteca da educação. Série 1. Escola. Volume 4)

IBGE-INSTITUTO BRASILEIRO DE GEOGRAFIA E ESTATÍSTICA. Indicadores sociais municipais: uma análise dos resultados do universo do censo demográfico $2010 . \quad$ Disponível em: <http://www.ibge.gov.br/home/estatistica/populacao/censo2010/indicadores_sociais_m unicipais/tabelas_pdf/tab5.pdf> Acesso em 15 dez. 2013.

IBGE-INSTITUTO BRASILEIRO DE GEOGRAFIA E ESTATÍSTICA. Tabela: População residente, por sexo e situação do domicílio, população residente de 10 anos ou mais de idade, total, alfabetizada e taxa de alfabetização, segundo os Municípios. In: Censo demográfico 2000: resultados do universo. Disponível em: 
<http://www.ibge.gov.br/home/estatistica/populacao/censo2000/defaulttab_munic.shtm >. Acesso em: 19 maio 2014.

IBGE-INSTITUTO BRASILEIRO DE GEOGRAFIA E ESTATÍSTICA. Síntese de indicadores sociais: uma análise das condições de vida da população brasileira: 2015 / IBGE, Coordenação de População e Indicadores Sociais. - Rio de Janeiro: IBGE, 2015.

OLIVEIRA, D. A. As políticas educacionais no governo Lula: rupturas e permanências. Revista Brasileira de Política e Administração Educacional. Volume 25, n. 2, Maio/Agosto 2009. P. 197-209. Disponível em: < http://www.seer.ufrgs.br/rbpae/article/download/19491/11317 > Acesso em: 15 dez. 2014.

RIBEIRO, M. L. S. História da educação brasileira: a organização escolar. 18 ed. Campinas: Autores Associados, 2003.

SAVIANI, D. A pedagogia no Brasil: história e teoria. 2 ed. Campinas: Autores Associados, 2012. p. 67 à 101.

SAVIANI. História das ideias pedagógicas no Brasil. 2 ed. rev. e. amp. Campinas: Autores Associados, 2008.

XAVIER, M. E.; RIBEIRO, M. L.; NORONHA; O. M. História da educação: a escola no Brasil. São Paulo: FTD, 1994.

\section{Como referenciar este artigo}

BRAGA, Ana Carolina; MAZZEU, Francisco José Carvalho. O analfabetismo no brasil: lições da história. Revista on line de Política e Gestão Educacional, Araraquara/SP, v.21, n.01, p. 24-46, 2017. Disponível em: <http://dx.doi.org/10.22633/rpge.v21.n.1.2017.9986>. ISSN: 1519-9029.

Submetido em: 13/01/2017

Aprovado em: 30/03/2017 